\title{
Determination of Hydroxylated Polybrominated Diphenyl Ethers in Blood from Baltic Grey Seals
}

\author{
Dennis Lindqvist ${ }^{1}$ (i) $\cdot$ Lillemor Asplund ${ }^{1}$
}

Received: 18 September 2018 / Accepted: 22 January 2019 / Published online: 13 February 2019

(c) The Author(s) 2019

\begin{abstract}
Naturally produced hydroxylated polybrominated diphenyl ethers (OH-PBDEs) have been extensively studied in the lower end of the Baltic Sea food web. Certain OH-PBDE congeners have displayed increasing concentrations over the last 30 years in herring (Clupea harengus) from the Baltic proper. However, studies on the top carnivores in the Baltic Sea are scarce. Quantitative data on OH-PBDEs exist for ringed seal (Pusa hispida) from the Gulf of Bothnia, but only a limited amount of data have been produced with regard to Baltic grey seal (Halichoerus grypus), and seals from the Baltic proper. A method was developed and evaluated for quantification of OH-PBDEs in coagulated whole blood. The method was applied on blood obtained from dead grey seals originating from different parts of the Baltic Sea. The levels of OH-PBDEs were observed to be low in the analyzed seals in comparison with reported levels in white-tailed sea eagle nestlings (Halizeetus albicilla), and some Baltic fish species. The levels of the dominant congener, 6-OH-BDE47, were statistically significantly higher in seals from the Baltic proper than in seals from the Gulf of Bothnia. Hydroxylated polychlorinated biphenyls (OH-PCBs) were observed to be of much higher concentration than the OH-PBDEs in the analyzed seals. The average concentration of the dominant $\mathrm{OH}-\mathrm{PCB}$ congener, 4-OH-CB107, was one order of magnitude greater than that of 6-OH-BDE47.
\end{abstract}

Keywords Phenols $\cdot$ OH-PBDEs $\cdot$ Seal $\cdot$ Blood $\cdot$ Analysis $\cdot$ Analytical methods

\section{Introduction}

The Baltic Sea is known to be heavily contaminated with environmental toxins. For example, more than a hundred different halogenated phenolic compounds (HPCs) have been indicated in Baltic salmon (Salmo salar) [1]. During the past two decades, naturally produced hydroxylated polybrominated diphenyl ethers (OH-PBDEs) have been reported as a major class of HPCs in the Baltic Sea biota [1-4]. These compounds add to the toxic load in Baltic wildlife. $\mathrm{OH}-$ PBDEs have been reported to be able to cause a number of adverse effects acting via several different mechanisms of

Electronic supplementary material The online version of this article (https://doi.org/10.1007/s41664-019-00084-1) contains supplementary material, which is available to authorized users.

Dennis Lindqvist

dennis.lindqvist@aces.su.se

1 Department of Environmental Science and Analytical Chemistry, Stockholm University, 10691 Stockholm, Sweden toxicity, such as through the disruption of oxidative phosphorylation (OXPHOS) [5, 6].

The grey seals (Halichoerus grypus) in the Baltic Sea have started to increase in numbers [7], and adverse health effects, including uteri occlusions and skull bone lesions, associated with classical contaminants such as polychlorinated biphenyls (PCBs) have decreased [8]. However, a downward trend in the blubber thickness has been observed during the beginning of the twenty-first century [9]. Although the exposure scenario regarding persistent organic pollutants such as PCBs and polybrominated diphenyl ethers (PBDEs) has been well studied in Baltic grey seals, the exposure to natural toxins such as OH-PBDEs has been given little attention. The concentration of some OH-PBDEs has been observed to have increased in Baltic herring (Clupea haren$g u s$ ), a major food source for grey seals, over the last three decades [10].

HPCs have been shown to have selective retention in blood [11] through association with blood proteins such as transthyretin [12], serum albumin [13], and lipoproteins [14]. This makes blood a suitable matrix to measure exposure to these types of compounds. However, a previous 
attempt to collect exposure data on OH-PBDEs in Baltic grey seals, using coagulated blood taken from deceased seals, indicated analytical difficulties [3]. The recoveries of the surrogate standards 4'-OH-BDE121 and 2'-OH-BDE28 were as low as $15 \pm 14 \%$ and $7 \pm 9 \%$, respectively [3].

The use of different analytical methods for determination of hydroxylated polychlorinated biphenyls (OH-PCBs) in different blood matrices has been summarized in a review article [15]. In 28 out of 41 cited studies, liquid-liquid extraction (LLE) methods, generally based on the procedure described by Hovander et al. [16] with minor modifications, were used [15]. For analysis of whole blood samples, the Hovander method was applied in seven out of eight cited studies [15]. This is also the method that provided poor recoveries of OH-PBDEs when used on coagulated grey seal blood from the Baltic Sea [3].

The Hovander method was originally developed and evaluated for human plasma [16]. However, it has been applied on a number of other blood matrices since then [15]. The method was recently evaluated for determination of $\mathrm{OH}-$ PBDEs in plasma and serum from a number of other species, and it was concluded that it was not compatible with all species [17]. Large variations in the recoveries of different OH-PBDEs from animal plasma were also revealed (from $<1$ to $>90 \%$ ), even regarding OH-PBDEs with similar physicochemical characteristics such as dissociation and partition constants [17]. It was suggested that hemolysis may have been the cause for the differences in recoveries between different species, as long-tailed duck (Clangula heymalis) and herring plasma that gave the poorest recoveries also had the most hemolysis [17]. Matrix effects from cell lysing during sampling were also suggested to be the cause for low recoveries of $\mathrm{OH}-\mathrm{PCB}$ s in whole blood from polar bears [18]. This suggest that whole blood coagulates may be particularly difficult matrices for quantification of OH-PBDEs and $\mathrm{OH}-\mathrm{PCBs}$.

The purpose of this study was to establish a method to accurately determine the concentration of OH-PBDEs in blood from dead Baltic grey seals. Further, to use the method for quantitative determination of OH-PBDEs in grey seals from different areas of the Baltic Sea. The goal was to determine if the levels differ between the Baltic proper and the Gulf of Bothnia and if there is any need for further monitoring of these compounds in Baltic grey seals.

\section{Experimental Section}

\subsection{Samples}

All blood samples in this study were donated by the Swedish museum of natural history. The blood (partially coagulated) was collected during autopsies of deceased grey seals sent into the museum after being found dead, often in commercial fishing equipment. Records of the size, gender and health status (e.g., blubber thickness) exist for all of the individuals. The quantified blood samples came from 12 seals originating from south to north along the Swedish east coast that were found dead between the years 2005 and 2007. Half of the animals originated from the Baltic proper and half from the Gulf of Bothnia. The full list of the animals that were analyzed for OH-PBDEs along with these records can be found in the electronic supplementary material (ESM; Table S1).

\subsection{Chemicals}

All solvents and reagents used in this study were of analytical grade from the established brands. Hemin $(\geq 97 \%)$ from porcine of HPLC quality was purchased from SigmaAldrich. All OH-PBDE standards used in the recovery study and as references for the quantitative analysis were synthesized in-house according to Marsh et al. [19] and Ryden [20]. All standards were of $>98 \%$ purity; further quality control of the standards such as mass spectrometry and NMR measurements can be found in the respective study $[19,20]$.

\subsection{Analytical Method}

\subsubsection{Extraction}

The blood samples $(5 \mathrm{~g})$ were extracted with a mixture of acetonitrile/2-propanol (MeCN/IPR; 3:1, $20 \mathrm{~mL}$ ) containing $1 \%$ acetic acid in a $50 \mathrm{~mL}$ polypropylene test tube. A few alundum granules with hard edgy surfaces were added to assist in the homogenization of the sample. The sample was mixed vigorously until a fine powder was obtained. The sample was then mixed again following the addition of diethyl ether (DEE; $10 \mathrm{~mL}$ ), followed by centrifugation at $2000 \mathrm{~g}$ for $5 \mathrm{~min}$. The supernatant was poured into a $100 \mathrm{~mL}$ separation funnel and the protein residue was re-extracted with a mixture of 2-methylpentane/DEE (3:1, $15 \mathrm{~mL})$ by mixing the sample with the solvents for roughly half a minute. After centrifugation, the extract was combined with the previous extract in the separation funnel.

Hydrochloric acid ( $\mathrm{HCl} ; 6 \mathrm{M}, 3 \mathrm{~mL})$ was added to the funnel, followed by water $(15 \mathrm{~mL})$ and 2-methylpentane (IHX; $15 \mathrm{~mL}$ ). The funnel was inverted 30 times, and the phases were allowed to separate. The aqueous lower phase was discarded and the organic upper phase was decanted into a new vessel. The volume of the extract was then reduced by evaporation until 3-5 $\mathrm{mL}$ remained before transferring the sample to a test tube and carefully bringing it to dryness by a gentle stream of nitrogen. 


\subsubsection{Cleanup and Isolation}

Free fatty acids and other carboxylic acids within the sample were methylated (neutralized) by adding water-free $\mathrm{HCl}$ in methanol $(1.25 \mathrm{M}, 1 \mathrm{~mL})$ and incubating the sample at $70{ }^{\circ} \mathrm{C}$ for $1 \mathrm{~h}$. After letting the sample cool down, water $(1 \mathrm{~mL})$ was added and the solution was extracted twice with IHX ( 2 and $1 \mathrm{~mL}$, respectively). The acidic HPCs were then isolated from the $3 \mathrm{~mL}$ of extract by two portions of potassium hydroxide in $50 \%$ ethanol $(0.5 \mathrm{M}, 1.5$ and $1 \mathrm{~mL})$. The combined alkaline extracts were acidified by $\mathrm{HCl}(6 \mathrm{M}, 0.5 \mathrm{~mL})$ and extracted with two portions of IHX ( 3 and $2 \mathrm{~mL}$ ). The $5 \mathrm{~mL}$ sample volume was then reduced to $1 \mathrm{~mL}$ by evaporation with a gentle stream of nitrogen and transferred to a $2 \mathrm{~mL}$ Eppendorf tube.

\subsubsection{Derivatization}

The HPCs were derivatized in a similar manner as previously described [21]. The $1 \mathrm{~mL}$ sample was mixed gently for a minimum of 2 min with a tetrabutylammonium hydrogen carbonate solution $(0.5 \mathrm{M}, 0.5 \mathrm{~mL})$ and $3.5 \%$ pentafluorobenzoyl chloride ( $\mathrm{PFBCl}$ ) in toluene $(5 \mu \mathrm{L})$. A $0.5 \mathrm{~mL}$ portion of trimethylpentane (TMP) was then added and the sample was shaken swiftly before centrifugation. The aqueous solution was then removed and discarded, and the remaining organic phase was treated with sulfuric acid $(>95 \%$, $0.5 \mathrm{~mL}$ ). The IHX in the isolated IHX/TMP mixture was removed by evaporation and the final sample volume was corrected to an appropriate level (average volume $0.2 \mathrm{~mL}$ ) in pure TMP.

\subsubsection{Instrumentation}

All analyses were conducted on an Agilent 7890A gas chromatograph (GC) (Agilent Technologies) with a multimode injector (MMI), coupled to a 5975C mass spectrometer (MS) working in the electron capture negative ionization mode (ECNI). A $5 \mu \mathrm{L}$ aliquot was injected in the solvent vent mode (at $80^{\circ} \mathrm{C}$ ). Excess derivatization reagent and solvent were vented out before the analytes were loaded onto the column with the aid of a 2 min pressure pulse ( $40 \mathrm{psi}$, at $\left.300{ }^{\circ} \mathrm{C}\right)$. Quantifications of OH-PBDEs were conducted using selected ion monitoring (SIM). A full description of the instrumental settings, including the injector and GC program along with the MS settings, can be found in the ESM.

\subsection{Method Evaluation}

The OH-PBDEs chosen for evaluation of the analytical method were compounds that were expected to be, if not absent, found in low concentrations in the samples (based on previous experience and a quick screening). They were also homologous with the same general structure and physicochemical properties as the substances of interest for the quantitative analyses. All commonly detected OH-PBDEs in the Baltic Sea, which have been suggested to stem from natural production, have the hydroxyl $(\mathrm{OH})$ group in ortho position in relation to the diphenyl ether bond [3, 22, 23]. Hence, these structures were of most interest for this study. However, in vitro experiments with isolated algal enzymes have also suggested para substituted OH-PBDEs as possible products of natural production [24] and, hence, these were also included in this study.

Two congeners each of tri-, tetra-, penta- and hexa-brominated OH-PBDEs were chosen for the evaluation. For each pair, one was chosen with the $\mathrm{OH}$ group in the ortho position and one was chosen with the $\mathrm{OH}$ group in the para position. From four individual seals, three sub-samples $(5 \mathrm{~g})$ were taken. The samples were spiked in three levels, one high (average concentration of $20 \mathrm{ng} / \mathrm{g}$ blood), one intermediate (average concentration of $4 \mathrm{ng} / \mathrm{g}$ blood), and one low (average concentration of $0.2 \mathrm{ng} / \mathrm{g}$ blood), by adding $100 \mu \mathrm{L}$ of a standard mixture in methanol to the sample. The samples were mixed and equilibrated for at least $1 \mathrm{~h}$ (but up to as long as $24 \mathrm{~h}$ ) before extraction. The extractions were spread out over several days. A volumetric standard was added prior to instrumental analyses and the recoveries were calculated against three point calibration curves.

\subsection{Quantitative Analyses}

Quantitative determinations of OH-PBDEs were conducted on 12 individual seals, 2 from each of the following locations: south Baltic proper, central Baltic proper, north Baltic proper, south Bothnian Sea, north Bothnian Sea, and Bothnia Bay. Two extractions (5 $\mathrm{g}$ each) were made on each sample, and these were pooled before quantification. The surrogate standard 2-OH-BDE123 ( $0.5 \mathrm{ng}$ per $5 \mathrm{~g}$ sample) was added prior to the extraction. The choice of the surrogate and spiking amount was decided following an initial screening of the samples. 2-OH-BDE123 also produced recoveries close to the average value (for all tested OH-PBDEs) in the method evaluation. The average recovery of 2-OH-BDE123 in quantitative study was determined to be $71 \pm 9 \%$. A blank sample was run in parallel to each set of samples analyzed. Quantifications were made against external calibration curves.

\section{Results and Discussion}

\subsection{Method Evaluation}

Generally, the method produced good recoveries (approximately $70 \%$ ) for the tested OH-PBDEs at all the concentrations (see Fig. 1). For the para-OH-PBDEs, specifically for 


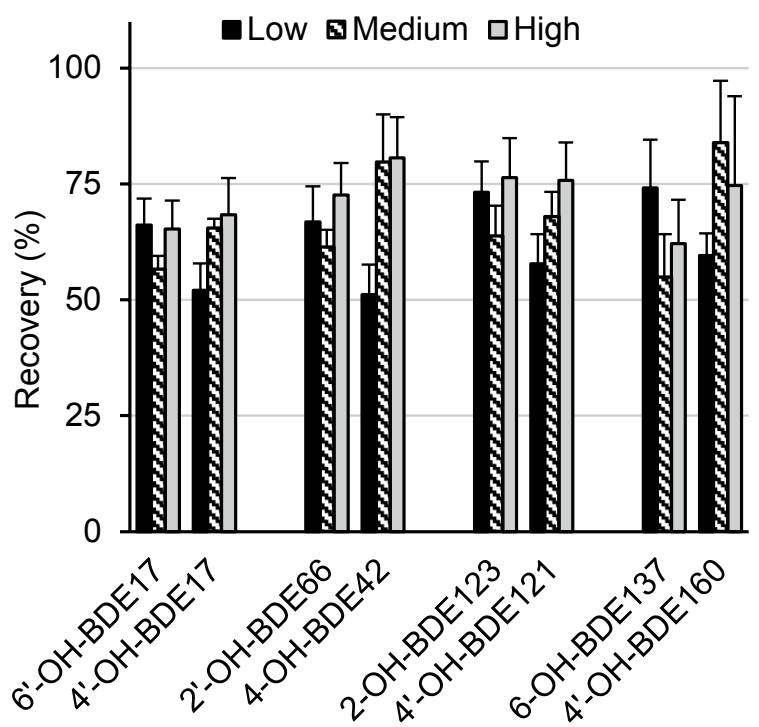

Fig. 1 Average recovery of each tested OH-PBDE, at three different concentrations, with four replicates (individuals) each. The error bars represents plus one standard deviation

4-OH-BDE42 and 4'-OH-BDE160, the recoveries were a bit lower at the lowest concentration. Additionally, the tri-brominated $\mathrm{OH}-\mathrm{PBDEs}$ displayed somewhat lower recoveries than the higher brominated congeners. This may be related to the polarity (losses during liquid-liquid extraction steps) and/or vapor pressure (losses during the evaporation of solvents). However, overall there were no major differences in the recoveries of the different congeners (see Fig. 1). This means that quantification of a broad spectrum of OH-PBDEs can be performed without the use of several surrogate standards to compensate for differences in the recoveries for $\mathrm{OH}-$ PBDEs with different substitution patterns.

\subsection{Method Development}

$\mathrm{MeCN}$ was chosen as the basis for the initial extraction because the homogenization proceeded smoothly with this solvent, and with the aid of some hard granules mixing for only a short time resulted in precipitation of the proteins as fine particles. The use of alcohols for the extraction such as IPR, as used in the Hovander method, was observed to be unpractical for application on coagulated seal blood. Alcohols made the blood prone to clotting, which made homogenization difficult and time consuming. For these blood samples, a three times larger volume of $\mathrm{MeCN}$ than blood (with dry weights of 30-35\%) was required to avoid clotting and achieve a smooth homogenization. However, adding a small amount of IPR to the MeCN (1:3) was actually found to be beneficial for the extraction as it seemed to disrupt some protein interaction resulting in even smaller particles, which increased the extraction efficiency. Following the homogenization, DEE was added to decrease the polarity. During the re-extraction of the remaining protein pellet, there were no issues with clotting and a less polar (more volatile) solvent composition could be used. The progression towards less polar solvents did not influence extraction efficiency to any major extent and the pellet could have been re-extracted with MeCN/IPR just as well. The progression was instead made to enable the liquid-liquid extraction step in which acidic water was added to remove the MeCN and IPR from the extract, thus leaving the HPCs in an IHX/DEE mixture that could easily be evaporated.

In the method by Hovander et al., $\mathrm{HCl}$ is used to denature proteins together with the solvents [16]. However, adding such strong acid to the blood coagulates analyzed in this study turned the extract dark red and made the recoveries drop. Even formic acid proved to be too strong. Hence, acetic acid was used in this study to protonate HPCs during the extraction. This gave a much clearer and cleaner extract. The redness of the extracts when using strong acids is the result of increased detachment of heme from hemoglobin. Dissociation of heme from hemoglobin under acidic condition is a well-known phenomenon. In the presence of oxygen, the free heme is quickly converted to ferriheme (hemin under acidic $\mathrm{pH}$ values), which is the basic principle of the socalled Sahli method used in the colorimetric determination of hemoglobin.

Hemin proved to have a large effect on the derivatization of OH-PBDEs when using diazomethane, specifically when the OH-PBDEs were dissolved in non-polar solvents together with hemin prior to the derivatization. The concentration of hemin and the time spent in non-polar solvents were the two most important factors for the recovery of HPCs. When stored overnight in hexane in the presence of low $\mu \mathrm{g}$ levels of pure hemin, the derivatization yield for some OH-PBDE congeners decreased to zero (particularly para substituted OH-PBDEs such as 4'-OH-BDE121 were affected). Poor recoveries when analyzing herring serum have previously been indicated to be partially related to poor yield during derivatization with diazomethane [22].

In the present study, a slightly modified version of the $\mathrm{PFBCl}$ method described by Jensen et al. [21] was used for derivatization. The derivatization procedure with $\mathrm{PFBCl}$ was observed to be less affected by the presence of hemin than diazomethane and it provided better recoveries than diazomethane when used on the coagulated seal blood samples.

$\mathrm{OH}-\mathrm{PBDEs}$ in biological matrices have previously been quantified as PFB esters using GC/ECNI-MS and monitoring of the phenolate ions in the SIM mode [25]. In the present study, a clear difference in fragmentation pattern was observed depending on the position of the $\mathrm{OH}$ group. The para-OH-PBDEs produced mostly bromide ions and fairly little phenolate ions, while the ortho-OH-PBDEs generally 
produced phenolate ions as the dominant fragment. metaOH-PBDEs also produced high relative abundance phenolate ions. However, at least for the tetra-brominated $\mathrm{OH}-$ PBDEs, the meta-OH-PBDEs could be differentiated from the ortho-OH-PBDEs by the relative abundance of two other fragments (M-107 and M-275). The differences in fragmentation for tetra-brominated OH-PBDEs with different $\mathrm{OH}$-positions are shown in Fig. 2. Increasing the ion source temperature generally resulted in better ionization efficiency and more phenolate ion fragments. However, this decreases the differences in fragmentation between metaand ortho-OH-PBDEs.

Although the derivatization with $\mathrm{PFBCl}$ improved the recoveries of OH-PBDEs compared to methylation with diazomethane, there are some limitations and issues associated with this method. Excess reagent can be difficult to remove chemically without endangering the formed HPC esters to lysis of the ester bond, and removal of excess reagent by evaporation prior to the GC analysis severely affected the recoveries. Other background interferences can also be formed, which due to the occurrence of fluorine may give large signals when using ECD or ECNI-MS. Furthermore, the limit of quantification (LOQ) varied significantly between individual seal samples due to a large difference in the background on the GC/MS system. In this regard, SIM analysis of the bromide ions following methylation of the $\mathrm{OH}-\mathrm{PBDEs}$ would have been a more favorable approach. On the other hand, the presented method enabled full-scan spectra to be obtained at low concentrations. During injection of pure standards, full-scan spectra with correct isotopic distribution for the phenolate ion could be secured from as little as $20 \mathrm{pg}$ injected, for the quantified OH-PBDEs.
The addition of a PFB group to OH-PBDEs also results in large analytes, thereby making the choice of the GC column, temperature program, and injection technique important. Hot splitless injection was observed to result in major discrimination according to size. Several techniques were tested using the programmable MMI to minimize this discrimination. The best results were gained when using temperature programmed injection followed by a 2 min pressure pulse. Additionally, a liquid ventilation step was included in the injection method, in which the amount of $\mathrm{PFBCl}$ reagent residue loaded onto the column could be greatly reduced. Choosing a narrower $(2 \mathrm{~mm})$ straight liner also reduced discrimination and increased the response compared to a wider $(4 \mathrm{~mm})$ single-tapper liner. Size discrimination during the injection of highly brominated PBDEs as well as the effects of the programmed temperature and pressure using a PTV injector have also previously been described [26].

With the settings used in this study, no analytes lighter than the PFB derivative of simple tri-brominated phenols should be quantified. For lighter HPCs such as mono- and di-brominated (or low chlorinated) phenols, temperatureprogrammed splitless injection gave the best result.

\subsection{Quantitative Analyses}

6-OH-BDE47 was the most abundant OH-PBDE in the seals with an average concentration of $0.69 \mathrm{ng} / \mathrm{g}$ dry weight. It was detected in all the samples and was the dominant OH-PBDE in all but one sample. Quantitative data are reported on dry weight (d.w.) basis due to the difference in water content between samples (from 63 to 77\%). The dry weights were determined gravimetrically on the dried
Fig. 2 Full-scan mass spectra of three tetra-brominated, $\mathrm{PFBCl}$ derivatized, OH-PBDEs, with the $\mathrm{OH}$ group in (from the top) ortho, meta, and para position respectively

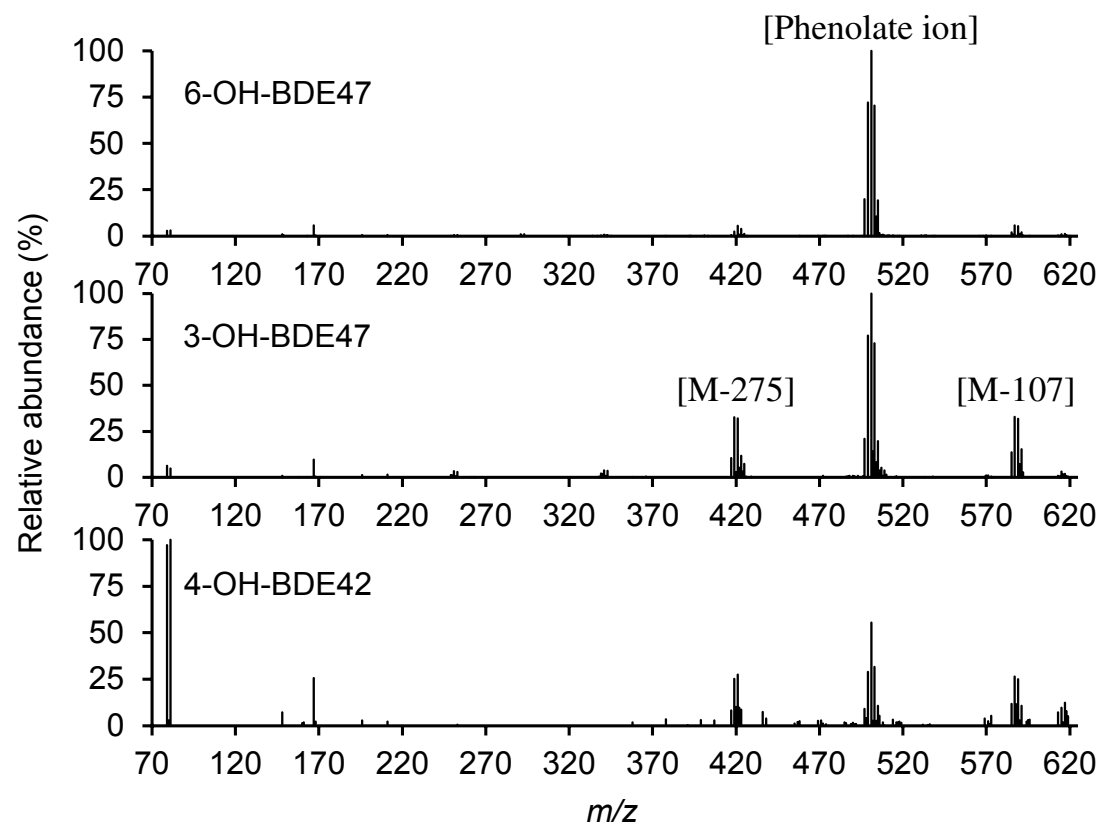


non-extractable protein residues following the extractions. The dominance of 6-OH-BDE47 was more pronounced in the Baltic proper than in the Gulf of Bothnia. 2'-OHBDE68 (average $0.050 \mathrm{ng} / \mathrm{g}$ d.w.) and 6-OH-BDE90/99 (average $0.15 \mathrm{ng} / \mathrm{g} \mathrm{d}$.w.) were also detected in all of the samples. 6'-OH-BDE49 was detected in 7 out of 12 seals, and 6-OH-BDE85 was found in 5 out of 12 seals. OH-PCBs were observed to dominate the full-scan chromatograms, with 4-OH-CB 107 being the most abundant. This OH-PCB was quantified in this study as well to compare the levels with that of the OH-PBDEs. OH-PCBs were not included in the recovery experiment and hence the quantitative data for 4-OH-CB 107 have a higher degree of uncertainty compared to that of the OH-PBDEs. The average concentration was estimated to be slightly greater than $9.0 \mathrm{ng} / \mathrm{g}$ d.w., i.e., an order of magnitude greater than that of 6-OH-BDE47. 4-OH-CB107 has previously been indicated as the dominant $\mathrm{OH}-\mathrm{PCB}$ in both Baltic ringed seals and grey seals [11,27].

By grouping the six seal samples originating from the Baltic proper together and comparing these to the six samples from the Gulf of Bothnia, clear differences in the levels of OH-PBDEs can been observed. In particular, 6-OHBDE47 was observed to be statistically significant higher in the Baltic proper ( $p=0.04$, two-sided $t$ test). This difference could not be observed for 4-OH-CB107 (Fig. 3). The levels of OH-PBDEs have previously been shown not to differ between white-tailed sea eagle nestlings from the Baltic proper and from the southern Bothnian Sea [28]. Similar results have also been presented for herring [29].

In the analyzed seals, the only other parameter except location (i.e., samples from Baltic prover vs. Gulf of Bothnia) that seemed to affect the concentration of 6-OH-BDE47 was age, cubs vs. adults, and cubs seemed to have higher levels. However, this comparison may also be affected by location, as a higher proportion of the cubs (2/3) originated from the Baltic proper than the adults (4/9) (see Fig. 3). The cubs in this comparison were animals that based on size were concluded to have been born earlier the same spring that they were found dead, while all other animals were considered adults in the comparison. This parameter also seemed to clearly affect the 4-OH-CB107 concentration. Another parameter that seemed to affect OH-PCB levels was the season (spring vs. autumn), where the spring samples seemed to contain higher concentrations of 4-OH-CB107 (Fig. 3). However, of the four spring samples, three were cubs, which of course affect this comparison. The gender, male $(n=8)$ vs. female $(n=4)$, and blubber thickness, fat $(n=7)$ vs. thin $(n=5$, animals were considered thin if the blubber thickness was less than $15 \mathrm{~mm}$ ) did not seem to affect either the OH-PBDE or OH-PCB concentrations (see Fig. 3). The full results with quantified values for each animal can be found in the ESM (Table S1).

The wet weight concentrations of 6-OH-BDE47, 6-OHBDE90 and 4-OH-CB107 in the grey seals originating from the Gulf of Bothnia were comparable to those values previously reported in ringed seals from the Gulf of Bothnia $[27,30]$. However, 2'-OH-BDE68 seems to be significantly lower in these grey seals than in the ringed seals studied by Routti et al. [30]. The average wet weight concentration of $6-\mathrm{OH}-\mathrm{BDE} 47$ in the seals from the Baltic proper $(0.35 \mathrm{ng} / \mathrm{g}$ w.w.) was much lower than the previously reported serum concentration from white-tailed sea eagle nestlings (Halizeetus albicilla) from the Baltic proper (2.35 ng/g w.w.) [28]. The levels were also lower than recently reported levels in
Fig. 3 Concentrations of 6-OHBDE47 and 4-OH-CB107 in grey seals from the Baltic Sea. The potential effect of different parameters on the concentrations is visualized by grouping the sample set (all 12 seals) into sets of two for comparison. The figures are essentially box and whiskers plots where the box has been exchanged for a diamond for easier comparison, the broadest point of the diamonds is the median concentration for the group while the top and bottom point is the 3 rd and 1st quartile, respectively; the whiskers represent the highest and lowest values for each group. The width of the diamond is proportional to the size of the sample (i.e., the amount of animals belonging to the group)

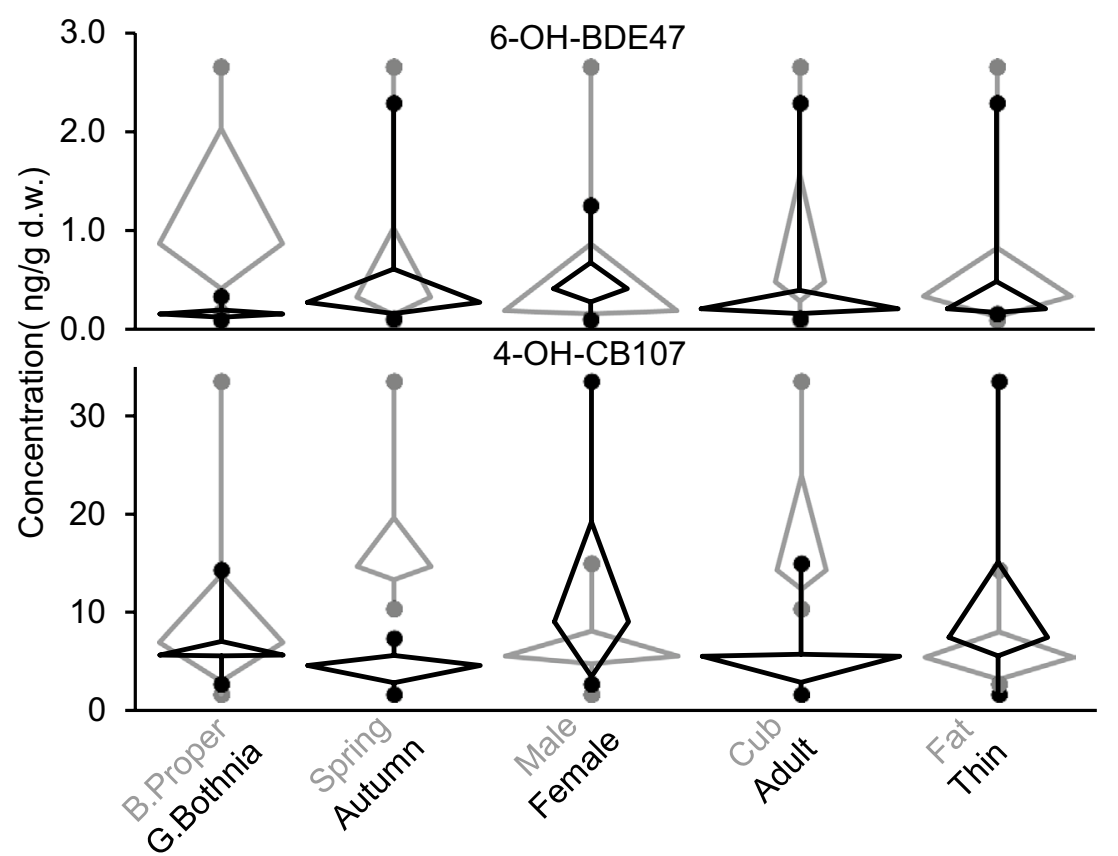


whole fish from the Baltic proper, both in perch (Perca fluviatilis, $6.6 \mathrm{ng} / \mathrm{g}$ w.w.) [31], and in herring ( $0.49 \mathrm{ng} / \mathrm{g} \mathrm{w.w.)}$ [29]. However, the levels were higher than the reported liver concentration in long-tailed duck from the Baltic proper (0.24 ng/g w.w.) [32].

Naturally produced OH-PBDEs (specifically 6-OHBDE47) have been indicated to have increased over the past three decades in Baltic herring [10], which is the major food source for Baltic grey seals [33]. At the same time, the levels of PCBs, i.e., the precursors of OH-PCBs, have decreased [34]. However, as indicated by this study the levels of $\mathrm{OH}-$ PCBs were still of much higher concentration than that of OH-PBDEs in Baltic grey seals during the first decade of the twenty-first century. It can hence be assumed that the Baltic grey seals have not been more exposed to HPCs in recent time than they were a few decades ago, assuming that the OH-PCB levels have decreased in some proportion to the PCB levels.

The Baltic grey seals exposure to OH-PBDEs should be followed up in the future, but the results presented here suggest that the efforts of continuous monitoring are better spent on other, more highly exposed, Baltic organisms.

Acknowledgements This project was financially supported by the Swedish Research Council for the Environment, Agriculture Sciences and Spatial Planning (FORMAS) via the OXPHOS project, and by Stockholm University's Strategic Marine Environment Research Fund, though the Baltic Ecosystem Adaptive Management (BEAM) project. The environmental research and monitoring unit at The Swedish Museum of Natural History, particularly Britt-Marie Bäcklin and Anna Roos, are gratefully acknowledged for supplying samples for this study.

\section{Compliance with Ethical Standards}

Conflict of interest The authors declare that they have no conflict of interest.

OpenAccess This article is distributed under the terms of the Creative Commons Attribution 4.0 International License (http://creativeco mmons.org/licenses/by/4.0/), which permits unrestricted use, distribution, and reproduction in any medium, provided you give appropriate credit to the original author(s) and the source, provide a link to the Creative Commons license, and indicate if changes were made.

\section{References}

1. Asplund LT, Athanasiadou M, Sjödin A, Bergman Å, Börjesson $\mathrm{H}$. Organohalogen substances in muscle, egg and blood from healthy Baltic salmon (Salmon salar) and Baltic salmon that produced offspring with the M74 syndrome. Ambio. 1999;28:67-76.

2. Athanasiadou M. Brominated flame retardants and related compounds in Baltic Sea wildlife-chemical analytical methodology and assessment. Ph.D. thesis, Department of environmental chemistry, Stockholm University, Stockholm, Sweden; 2003.

3. Löfstrand K. Trends and exposure of naturally produced brominated substances in Baltic biota-with focus on OH-PBDEs,
MeO-PBDEs and PBDDs. Ph.D. thesis, Department of materials and environmental chemistry, Stockholm University, Stockholm, Sweden; 2011.

4. Marsh G, Athanasiadou M, Bergman $\AA$, Asplund L. Identification of hydroxylated and methoxylated polybrominated diphenyl ethers in Baltic Sea salmon (Salmo salar) blood. Environ Sci Technol. 2004;38:10-8

5. van Boxtel AL, Kamstra JH, Cenijn PH, Pieterse B, Wagner MJ, Antink M, Krab K, van der Burg B, Marsh G, Brouwer A, Legler J. Microarray analysis reveals a mechanism of phenolic polybrominated diphenyl ether toxicity in zebrafish. Environ Sci Technol. 2008;42:1773-9.

6. Legradi J, Dahlberg AK, Cenijn P, Marsh G, Asplund L, Bergman A, Legler J. Disruption of oxidative phosphorylation (OXPHOS) by hydroxylated polybrominated diphenyl ethers (OH-PBDEs) present in the marine environment. Environ Sci Technol. 2014;48:14703-11.

7. Harding KC, Härkönen T, Helander B, Karlsson O. Status of Baltic grey seals: population assessment and extinction risk. NAMCO Sci Publ. 2007;6:33-56.

8. Bergman A. Health condition of the Baltic grey seal (Halichoerus grypus) during two decades. Gynaecological health improvement but increased prevalence of colonic ulcers. APMIS. 1999;107:270-82.

9. Bäcklin BM, Moraeus C, Kauhala K, Isomursu M. Nutritional status of seals. In: HELCOM Core Indicator Report. HELCOM. 2013. http://helcom.fi/Core\%20Indicators/HELCOM-CoreIndica tor-Nutritional_status_of_seals.pdf. Accessed 4 June 2018.

10. Faxneld S, Nyberg E, Danielsson S, Bignert A. Miljögifter i biota. Havet. 2014;2013(2014):78-81.

11. Bergman $\AA$, Klasson-Wehler E, Kuroki H. Selective retention of hydroxylated PCB metabolites in blood. Environ Health Perspect. 1994;102:464-9.

12. Lans MC, Klasson-Wehler E, Willemsen M, Meussen E, Safe $S$, Brouwer A. Structure-dependent, competitive interaction of hydroxy-polychlorobiphenyls, -dibenzo- $p$-dioxins and -dibenzofurans with human transthyretin. Chem Biol Interact. 1993;88:7-21.

13. Ma Q, Bai H, Wang C, Xi GC, Zhang Q, Meng XS, Chen YX, Li JR, Ma HJ, Guo LH. Investigation of noncovalent interactions between hydroxylated polybrominated diphenyl ethers and bovine serum albumin using electrospray ionization-ion mobility-mass spectrometry. Int J Mass Spectrom. 2014;357:34-44.

14. Yamauchi K, Sai G. Characterization of plasma triiodophenol binding proteins in vertebrates and tissue distribution of triiodophenol in Rana catesbeiana tadpoles. Comp Biochem Physiol Part C Toxicol Pharmacol. 2011;153C:328-35.

15. Quinete N, Schettgen T, Bertram J, Kraus T. Analytical approaches for the determination of PCB metabolites in blood: a review. Anal Bioanal Chem. 2014;406:6151-64.

16. Hovander L, Athanasiadou M, Asplund L, Jensen S, KlassonWehler E. Extraction and cleanup methods for analysis of phenolic and neutral organohalogens in plasma. J Anal Toxicol. 2000;24:696-703.

17. Dahlberg AK, Norrgran J, Hovander L, Bergman $\AA$, Asplund L. Recovery discrepancies of OH-PBDEs and polybromophenols in human plasma and cat serum versus herring and long-tailed duck plasma. Chemosphere. 2014;94:97-103.

18. Sandala GM, Sonne-Hansen C, Dietz R, Muir DCG, Valters K, Bennett ER, Born EW, Letcher RJ. Hydroxylated and methyl sulfone PCB metabolites in adipose and whole blood of polar bear (Ursus maritimus) from East Greenland. Sci Total Environ. 2004;331:125-41.

19. Marsh G, Stenutz R, Bergman A. Synthesis of hydroxylated and methoxylated polybrominated diphenyl ethers - Natural products 
and potential polybrominated diphenyl ether metabolites. Eur J Org Chem. 2003;14:2566-76.

20. Ryden A. Synthesis of organobromines as a tool for their characterisation and environmental occurrence assessment. Ph.D. thesis, Department of materials and environmental chemistry, Stockholm University, Stockholm, Sweden; 2013.

21. Jensen S, Lindqvist D, Asplund L. Lipid extraction and determination of halogenated phenols and alkylphenols as their pentafluorobenzoyl derivatives in marine organisms. J Agric Food Chem. 2009;57:5872-7.

22. Dahlberg AK. Environmentally relevant chemical disruptors of oxidative phosphorylation in Baltic Sea biota - Exposure and toxic potentials. Ph.D. thesis, Department of environmental science and analytical chemistry, Stockholm University, Stockholm, Sweden; 2015.

23. Malmvärn A. Brominated natural products at different trophic levels in the Baltic Sea. Identification of polybrominated dioxins, hydroxylated and methoxylated diphenyl ethers. Ph.D. thesis, Department of environmental chemistry, Stockholm University, Stockholm, Sweden; 2007.

24. Lin K, Gan J, Liu W. Production of hydroxylated polybrominated diphenyl ethers from bromophenols by bromoperoxidase-catalyzed dimerization. Environ Sci Technol. 2014;48:11977-83.

25. Lindqvist D, Jensen S, Asplund L. Lipid-soluble conjugates of hydroxylated polybrominated diphenyl ethers in blue mussels from the Baltic Sea. Environ Sci Pollut Res. 2014;21:954-61.

26. Björklund J, Tollbäck P, Hiärne C, Dyremark E, Östman C. Influence of the injection technique and the column system on gas chromatographic determination of polybrominated diphenyl ethers. J Chromatogr A. 2004;1041:201-10.

27. Routti H, Letcher RJ, Arukwe A, van Bavel B, Yoccoz NG, Chu $\mathrm{S}$, Gabrielsen GW. Biotransformation of PCBs in relation to phase I and II xenobiotic-metabolizing enzyme activities in ringed seals (Phoca hispida) from Svalbard and the Baltic Sea. Environ Sci Technol. 2008;42:8952-8.
28. Nordlöf U. Levels of organohalogen compounds in White-tailed sea eagles (Haliaeetus albicilla) in relation to reproduction impairment in Bothnian Sea. Ph.D. thesis, Department of applied environmental science, Stockholm University, Stockholm, Sweden; 2012.

29. Dahlberg AK, Bignert A, Legradi J, Legler J, Asplund L. Anthropogenic and naturally produced brominated substances in Baltic herring (Clupea harengus membras) from two sites in the Baltic Sea. Chemosphere. 2016;144:2408-14.

30. Routti H, Letcher RJ, Chu S, van Bavel B, Gabrielsen GW. Polybrominated diphenyl ethers and their hydroxylated analogues in ringed seals (Phoca hispida) from Svalbard and the Baltic Sea. Environ Sci Technol. 2009;43:3494-9.

31. Dahlgren E, Lindqvist D, Dahlgren H, Asplund L, Lehtilä K. Trophic transfer of naturally produced brominated aromatic compounds in a Baltic Sea food chain. Chemosphere. 2016;144:1597-604.

32. Dahlberg AK, Lindberg Chen V, Larsson K, Bergman Å, Asplund L. Hydroxylated and methoxylated polybrominated diphenyl ethers in long-tailed ducks (Clangula hyemalis) and their main food, Baltic blue mussels (Mytilus trossulus $\times$ Mytilus edulis). Chemosphere. 2016;144:1475-83.

33. Havs- och vattenmyndigheten. Nationell förvaltningsplan för gråsäl (Halichoerus grypus) i Östersjön. Havs- och vattenmyndigheten. 2012. https://www.havochvatten.se/download/18.576c1 bad139e467697d80006088/1348912841150/forvaltningspla n-grasal-120924.pdf. Accessed 15 June 2018.

34. Bignert A, Danielsson S, Strandmark A, Nyberg E, Asplund L, Eriksson U, Berger U, Willander A, Haglund P. Comments concerning the national Swedish monitoring programme in marine biota, 2008. Swedish Museum of Natural History. 2008. http:// www.nrm.se/download/18.61d98c3a11a91af311a80001279/ Marina+programmet+2008.pdf. Accessed 22 June 2018. 